\title{
Numerical investigation on the effect of varying the number of flow dividers on Z- Shaped membrane heat exchanger performance
}

\author{
Mohammad Shakir Nasif a, ${ }^{\text {a }}$, Ra'fat AI-Waked ${ }^{\text {b }}$, Firas Ismail c \\ a Mechanical Engineering Department, Universiti Teknologi PETRONAS, Perak, Malaysia \\ b German Jordanian University, School of Applied Technical Sciences, Amman, Jordan \\ c Power Generation Research Centre, College of Engineering, Universiti Tenaga Nasional, Selangor, Malaysia \\ * Corresponding author: mohammad.nasif@utp.edu.my
}

\section{Article history}

Received 12 January 2019

Revised 14 May 2019

Accepted 10 October 2019

Published Online 2 February 2020

\begin{abstract}
To reduce building energy consumption and to improve indoor air quality, it is necessary the use heat recovery such as air-to-air fixed-plates enthalpy heat exchanger in mechanical ventilation. Prediction of enthalpy performance by utilizing CFD simulation is challenging since most commercial software do not simulate moisture transfer. In this research, a Z-shaped membrane heat exchanger which is used for building energy recovery systems was modeled by using commercial CFD software (FLUENT). Kraft paper of $45 \mathrm{gsm}$ was used as the heat exchanger heat and moisture transfer surface. A User Define Function (UDF) code was developed and incorporated in the CFD software to enable the software to model moisture transfer through the membrane. This model is used to investigate the performance of Z-Shaped heat exchanger when the number of flow dividers within the heat exchanger is varied. It was found that a $21 \%$ increase in the effectiveness was achieved when the number of ribs was increased from no ribs to 5 ribs. However, increasing the number of ribs from 5 to 11 only demonstrates minor effect. Therefore, no significant improvement is noticed when the number of ribs is increased beyond 5 which is attributed to air flow distribution which because more uniform when number of ribs is increased. However, the flow is already uniform when 5 ribs where used, hence increasing the ribs to 11 will not improve the flow distribution further.
\end{abstract}

Keywords: Membrane heat exchanger, latent effectiveness, moisture transfer

\section{INTRODUCTION}

Minimizing energy consumption and improving indoor air quality in buildings have made incorporating heat recovery into mechanical ventilation a fundamental practice (Nasif et al., 2012: Zhang et al., 2010; Vakiloroaya et al., 2014; Ashrae, 2016). Fixed-plate enthalpy heat exchanger is an effective energy recovery device in HVAC system. It is a static low-cost device which has no moving parts and requires less maintenance than other energy recovery systems. The operating principle of this device is that warm and humid air flows in to an air path in a heat exchanger and cold air which is less humid will be directed to another air stream. The two streams are separated by a permeable thin sheet (such as membrane) (Nasif et al., 2012).

Due to gradient in temperature and moisture content between the two streams, heat and moisture will be transferred across the permeable surface. The heat and moisture transportation from the hot and humid stream to the membrane surface is achieved by convection Subsequently by conduction of heat and diffusion of moisture which takes place through the permeable surface. Finally, heat and moisture are then transported by convection from the permeable thin sheet surface to the cold and less humid stream. As a result, the ambient fresh air will be dehumidified and cooled in the heat exchanger before it flows in to the air conditioning system. This process provides $100 \%$ fresh air to condition rooms and save energy due to the pre-cooling and dehumidification process occurs in the heat exchanger. In fact, supplying $100 \%$ fresh air has become essential in many buildings as many building codes demands better indoor air quality (Ye et al., 2017; Mardiana-Idayu and Riffat, 2012).
Fabricating the enthalpy heat exchangers and assembling themis known to be costly. Hence, to save cost, the present work chose to utilize Computational Fluid Dynamics (CFD) software to simulate and predict its performance. However, available commercial CFD software do not simulate moisture diffusion through porous material such as membranes. Hence, User Define Function (UDF) codes need to be developed and incorporated in the software in order to enable the software to simulate the heat and moisture transfer process (Al Wakeda et al., 2018; Nasif et al., 2012).

Nasif et al. (2012) used FLUENT CFD software to model Z-shaped heat exchanger configuration to study moisture and temperature distribution in the enthalpy exchanger. They developed a nondimensional sensible-latent effectiveness ratio by developing UDF code to simulate moisture transfer. In other words, they coupled heat transfer with moisture transfer. However, to carry out their modeling, they need to determine the effective values experimentally.

Zhang (2010) modeled quasi-counter flow heat exchanger by using FLUENT. In the developed model, Zhang solved the mass transfer problem using the heat-mass transfer analogy where he made the values of Prandtl number (Pr) and thermal diffusion in the heat transfer model and make them the same as Schmidt number $(\mathrm{Sc})$ and mass diffusion. In other words, the mass transfer problem is solved as a heat transfer problem and presented his results in non-dimensional format. Yaïci et al. (2013) developed a 2D CFD model of the membrane heat exchanger. They utilized constant air properties in their model and did not consider heat caused by moisture diffusion through the membrane. Al Waked et al. (2013) developed a 3-D CFD model by using UDF code which is capable of simulating moisture transfer process across constant 
moisture transfer resistance membrane by using FLUENT. Their results showed that counter-flow configuration is sensitive to the mesh central distance in the perpendicular direction as compared to other flow configurations (such as cross and parallel flow). Al Waked et al. (2015) then developed another UDF code which is incorporated in FLUENT CFD model. This model simulates moisture transfer across the membrane whereby moisture transfer resistance is not constant. They validated their model against past research.

Min and Duan (2016) performed comparison investigation between different mathematical and numerical methods developed to evaluate the membrane heat exchanger performance. They concluded that numerical method can provide not only more precise effectiveness as compared to the effectiveness-NTU methods. It also provides detailed distributions of various flow parameters. They also highlighted the performance can be enhanced when adsorption heat is considered in the modeling.

Sabek et al. (2018) performed numerical simulation of membrane heat exchanger to study the effect of adding obstacles in the heat exchanger on its performance. They found that round obstacles are more impactful on the heat exchanger performance as compared with rectangular, triangular obstacles.

This study extended the study by Nasif et al. (2012) on Z-shaped heat exchanger. The exchanger utilizes $45 \mathrm{gsm}$ permeable Kraft paper as heat and moisture transfer surface. The existing heat exchanger had five flow dividers ribs which were used to make air flow more uniform and support the permeable paper in the heat exchanger. Theoretically, increasing the number of ribs will increase the pressure drop across the heat exchanger. In this research, the number of ribs was varied to investigate its effect on heat exchanger heat and moisture transfer effectiveness and consequently on the amount of heat recovered and moisture dehumidified. This was achieved by developing UDF code utilizing $\mathrm{C}++$, and by using Lewis number to obtain air moisture content at the permeable surface boundary. Hence, this enabled the CFD software FLUENT to simulate moisture transfer. This UDF code is deferent than the UDF code developed by Nasif et al. (2012), which utilizes non-dimensional sensible-latent effectiveness ratio to obtain air moisture content at the paper boundary.

\section{MEASUREMENT OF HEAT EXCHANGER PERFORMANCE}

The experimental rig, shown schematically in Fig. 1, was performed by Nasif et al. (2012). The test rig consists of two air streams ducts. In the hot stream, air is heated and steam is injected, meanwhile in the cold stream, ambient air is supplied. The passage of the cold air stream is laterally inverted from the passage direction of the hot air stream as shown in Fig. 2.

The test section consists of $0.72 \mathrm{~m} \times 0.3 \mathrm{~m} \mathrm{Z}$-shaped heat exchanger which is made of 98 plastic frames with 49-inlet air passages in each of the air stream. The heat exchanger has five flow dividers which is provided to obtain uniform flow distribution and to support the permeable paper. The heat and moisture transfer surface used is $78 \mu \mathrm{m}$ thick 45 gsm paper.

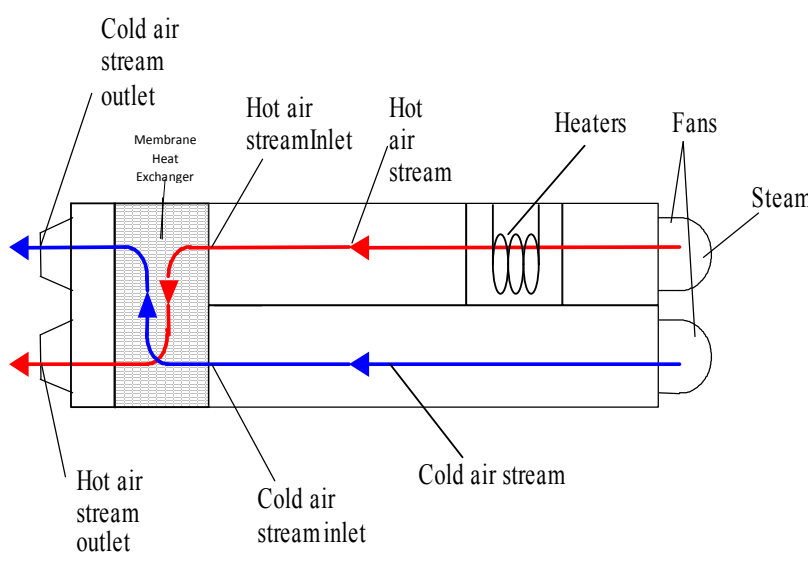

Fig. 1 Experimental test rig (Nasif et al., 2012).
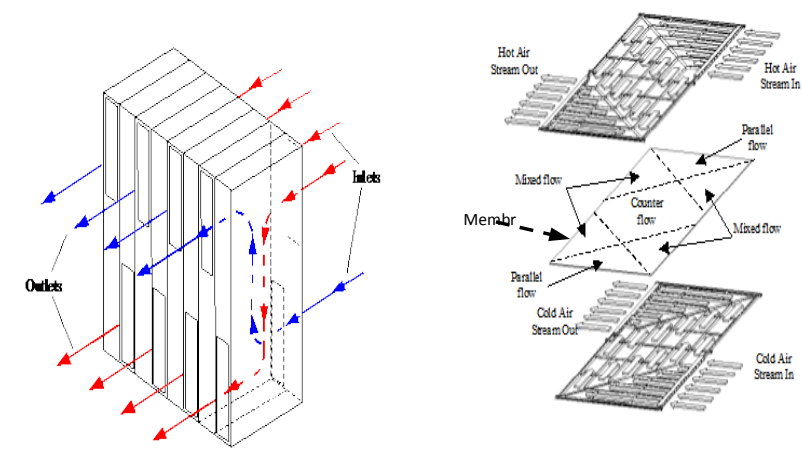

Fig. 2 Heat exchanger flow paths configuration (Nasif et al., 2012).

In this experiment, air velocity was varied from $1.5 \mathrm{~m} / \mathrm{s}$ to $3.2 \mathrm{~m} / \mathrm{s}$. Air temperature and moisture content were measured at the air stream inlets and outlets. The static pressure drop between the heat exchanger inlet and outlet also was measured using static pressure points which was drilled through the test rig walls close to the inlets and outlets.

The two points were connected to a manometer to measure the pressure drop across the heat exchanger. The heat exchanger effectiveness was calculated from the measurement of air temperature and moisture content at both streams inlets and outlets by using the following effectiveness equations:

Sensible Effectiveness

$$
\varepsilon_{s}=\frac{\dot{m} c_{p a}\left(T_{h i}-T_{h o}\right)}{\left(\dot{m} c_{p a}\right)_{\min }\left(T_{h i}-T_{C i}\right)}
$$

Latent Effectiveness

$$
\varepsilon_{L}=\frac{\dot{m} h_{f g}\left(\omega_{h i}-\omega_{h o}\right)}{\dot{m}_{\min } h_{f g}\left(\omega_{h i}-\omega_{C i}\right)}
$$

where $\varepsilon_{s}$, and $\varepsilon_{L}$ represent sensible and latent total effectiveness, respectively. $T_{h i}, T_{c i}, T_{h o}, T_{c o}$ represent air temperature at the heat exchanger inlets and outlet. $\omega_{h i}, \omega_{h o}, \omega_{c i}, \omega_{c o}$ represent air humidity ratio at the inlet and outlets.

Fig. 3 shows the effectiveness variation with air velocity where the effectiveness was inversely proportional to air velocity. It is expected that increasing the air velocity would increase the heat and mass transfer coefficients, but this is offset by the corresponding decrease in air residence time in the heat exchanger which caused the effectiveness to decrease.

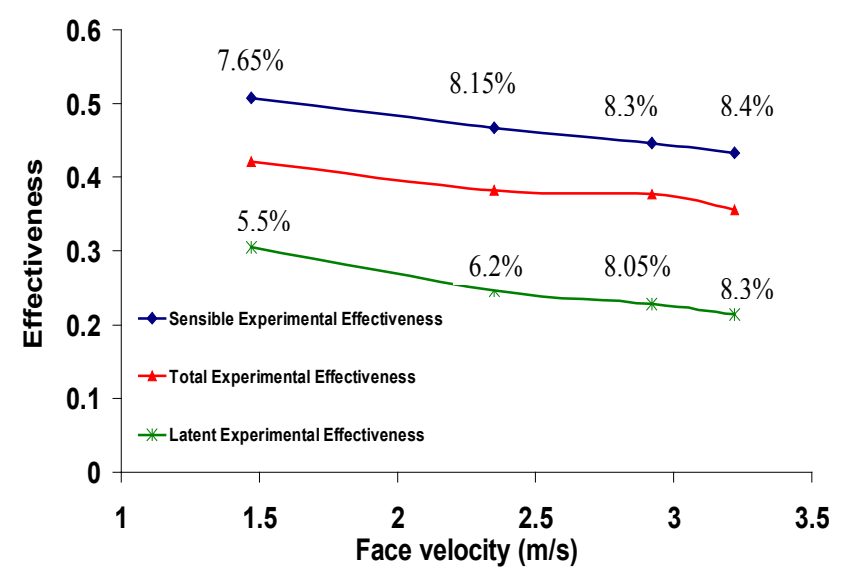

Fig. 3 Experimental effectiveness for $45 \mathrm{gsm}$ paper heat exchanger (percentage shown in graphs indicate averaged experimental uncertainty) (Nasif et al., 2012). 


\section{COMPUTATIONAL FLUID DYNAMICS MODELING}

As mentioned, the effect of varying the number of flow divider ribs which act as support structure to hold the permeable surface on the heat exchanger effectiveness was investigated by using CFD commercial software FLUENT. In order to carry out this investigation, the model of the Z-shaped five ribs heat exchanger performance should be validated against effectiveness calculated from the experiment.

In FLUENT software, Finite-Volume Differencing scheme was used to solve the algebraic equations formed from discretization of Navier Stoke and energy equations. Second order upwind discretization scheme was used to discretize the pressure, momentum, and energy equations. Semi implicit method for pressure linked equationconsistent (SIMPLEC) algorithm was used for the calculation of the pressure and air velocity in the heat exchanger.

As mentioned, commercial CFD software do not simulate moisture transfer across the membrane. Therefore, User Define Function has been developed by using Lewis number to obtain the air moisture content at the permeable paper surface boundary. Lewis number is represented as

$$
L e=\frac{\lambda_{\text {air }}}{C_{\text {p moist air }} D_{\text {water-air }} \rho_{\text {moist air }}}
$$

Air properties including air thermal conductivity $\left(\lambda_{\text {air }}\right)$ and water in air diffusivity $\left(D_{\text {water-air }}\right)$ with varied temperatures were obtained from air properties tables Air properties were plotted against temperature and best fit line equations were incorporated into the UDF. FLUENT software provides the temperature at the permeable paper surface boundary by solving the energy equation.

Lewis equation requires Lewis number value to provide moist air density $\left(\rho_{\text {moistair }}\right)$ at the permeable paper surface boundary. It has been reported that for enthalpy heat exchangers, Lewis number was 0.81 (AlWaked et al., 2015; Nasif et al., 2013). Hence, $\rho_{\text {moist }}$ air at the permeable paper surface boundary in the hot and moist stream can be calculated. The vapor density in the air is represented as

$$
\rho_{\text {vapour }}=\rho_{\text {moist air }}-\rho_{\text {dry air }} \text {. }
$$

FLUENT provides the air temperature at the paper boundary, while dry air density is obtained in a similar way as $\lambda_{\text {air }}$ and $D_{\text {water-air. }}$ By substituting it with $\rho$ moist air in the following equation, $\rho_{\text {vapour }}$ can be determined and incorporated in the UDF code. Air moisture content is calculated from

$$
\begin{gathered}
\omega_{\text {hot stream }}=\frac{\rho_{\text {vapour }}}{\rho_{\text {moist air }}} \\
\dot{\bar{m}}_{\text {moisture }}=\frac{\left(\omega_{\text {paper hot stream }}-\omega_{\text {paper cold stream }}\right)}{R_{\text {moisture resis tance }}}
\end{gathered}
$$

To enable FLUENT to simulate moisture transfer in the heat exchanger, air moisture content at the cold stream permeable surface boundary is needed which can be obtained from a report of Nasif et al., 2012. The $45 \mathrm{gsm}$ paper moisture transfer resistant was found to be 70 $\mathrm{m}^{2} \mathrm{~s} / \mathrm{kg}$ which was obtained from permeability measurement detailed in the previous work (Nasif et al., 2012). In the heat exchanger cold air stream, the moisture at the paper surface boundary at each cell in the model is obtained from the air mass flow rate from

$$
\dot{\bar{m}}_{\text {moistur }}=\dot{m}_{\text {cell moist air }} \omega_{\text {paper cold stream }}
$$

where $\dot{m}_{\text {moist air }}$ is the moist air mass flowrate at the cold stream which flows through each cell at the surface of permeable paper. Substituting equation 7 into equation 6 to get the moisture content at the cold air stream gives

$$
\omega_{\text {papercold stream }}=\frac{\omega_{\text {paperhot stream }}}{\dot{m}_{\text {cell moist air }} R_{\text {moist resistance }}+1}
$$

Air and vapor thermodynamic properties were obtained as a function of air temperature (Cengel, 2006; Kroger, 2004). Hence the air moisture content at the permeable paper surface boundary in the cold stream is obtained.

At the stream air inlet, velocity inlet boundary condition is used and at the heat exchanger outlet, outflow boundary condition is utilized in the CFD model. To reduce computational time given the fact that both hot and cold streams in the heat exchangers are symmetrical hence symmetry boundary condition is used where half of each flow path modeled at each side of the permeable surface of the paper.

From Fig. 3, the Reynolds number range at each flow path of the air velocity used in the test was from 2300 to 5500 . Therefore, turbulent $\mathrm{k}-\varepsilon$ renormalization group ( $\mathrm{k}-\varepsilon \mathrm{RNG})$ is used. Mesh independency investigation was carried out to optimize the number of cells used in the model. It was found that increasing the number of mesh from 250,000 to 300,000 gave $2 \%$ difference in the results. Therefore 250,000 cells were used in the simulation.

CFD simulation was carried out at the tested air velocity. Fig. 4 shows that the CFD simulation results from using Lewis number method are in reasonable agreement with the measured effectiveness values. Validation of the pressure drop results across the heat exchanger was carried out and Fig. 5 shows that good agreement was achieved between the pressure drop predictions against experimental measurement. Since the CFD model is validated against experimental measurement, hence it can be used to predict the heat exchanger performance when the number of ribs is varied. Heat exchanger models were developed for no ribs, one rib, two ribs, three ribs, five ribs, and eleven ribs. The simulation was run at the same tested inlet air velocities, air temperature, and moisture content.

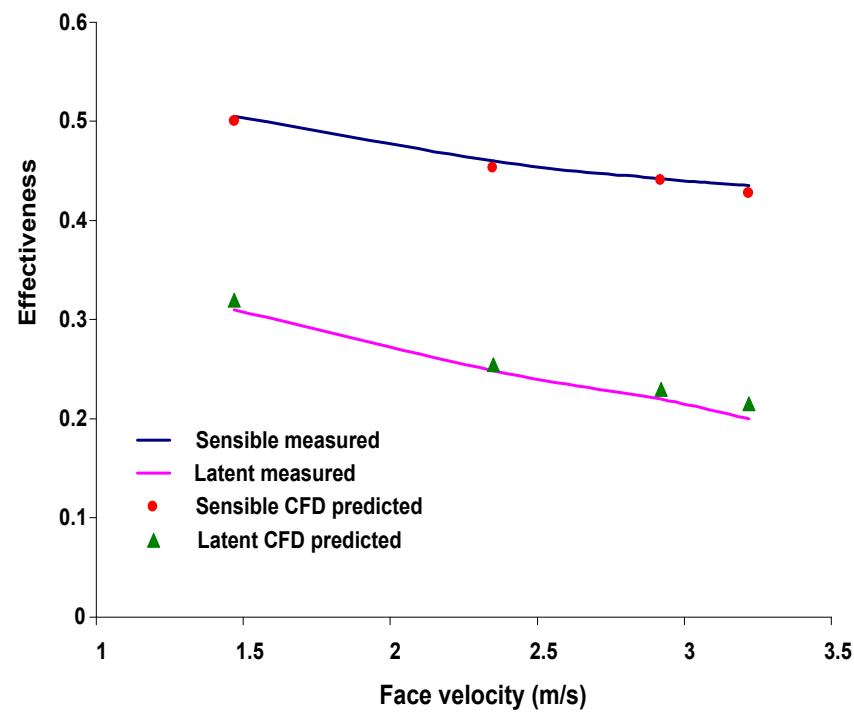

Fig. 4 Heat exchanger modeled and measured effectiveness. 


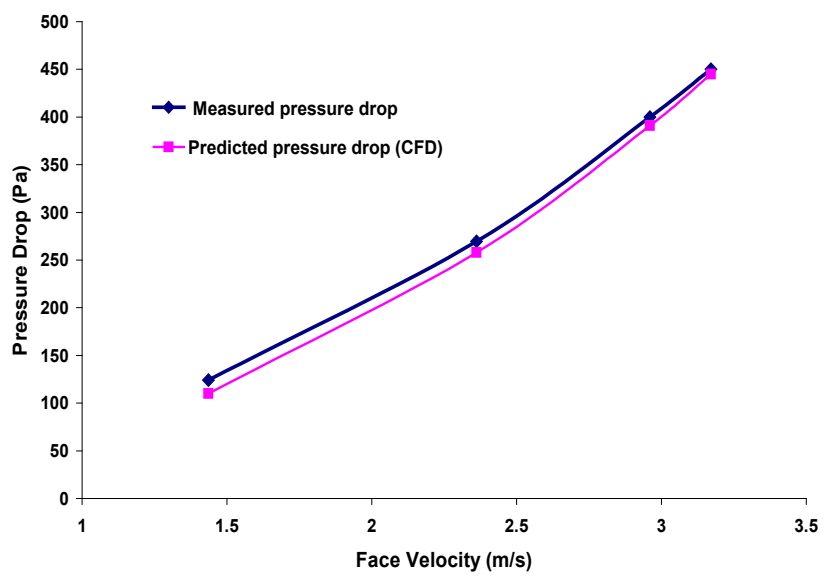

Fig. 5 Heat exchanger modeled and measured pressure drop.

Figs. 6 and 7 show the sensible and latent effectiveness variation against air velocity. As seen the effectiveness increased rapidly when one rib is used, the sensible and latent effectiveness increased by $9 \%$ relative to the heat exchanger without ribs. However, when the number of ribs was increased to two, both sensible and latent effectiveness increased by about $4 \%$ relative to the single rib heat exchanger. The effectiveness and the values increased further by the approximately 7 $\%$ when the number of ribs increased to three relative to the 2 ribs heat exchanger and by $5 \%$ when 5 ribs were used.

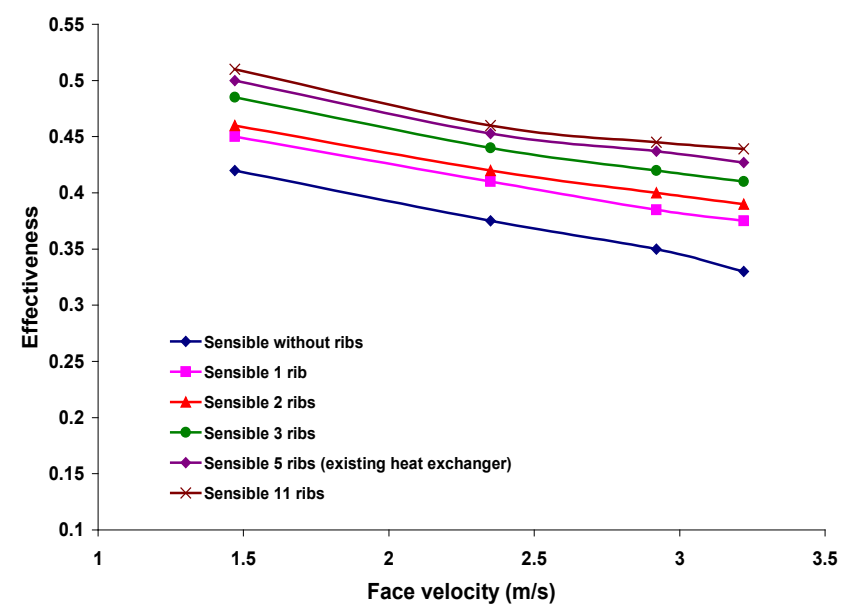

Fig. 6 Heat exchanger modeled sensible effectiveness for different number of flow dividers.

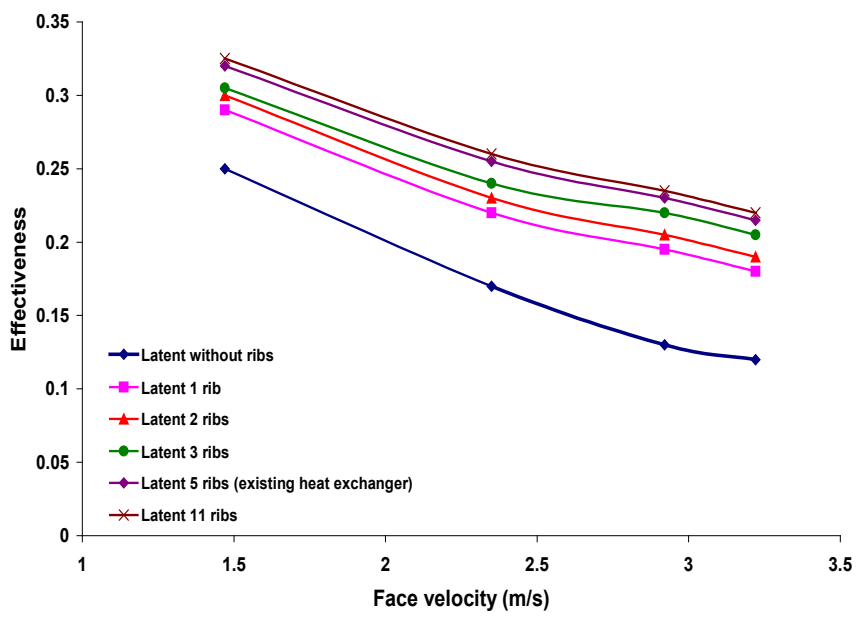

Fig. 7 Heat exchanger modeled latent effectiveness for different number of flow dividers.
However, the increase in the effectiveness values became marginal when an 11-rib heat exchanger was used as the effectiveness value increased by only $0.8 \%$ relative to the 5 ribs design. It can be concluded that increasing the number of ribs from 5 to 11 has only a marginal effect on effectiveness as the flow, temperature and moisture distribution are already uniform. Therefore, no significant improvement is noticed when the number of ribs is increased to 11 . This is attributed to the air velocity distribution within the heat exchanger.

As seen in Fig. 8, there is low velocity zone in no flow ribs heat exchanger (blue color contour) because there is no flow divider to make the flow uniform. This zone decreased when flow dividers were used. When 5 flow dividers were introduced the low velocity flow zone became very small and when 11 flow dividers where utilized, there was little difference in the flow profile as compared with 5 flow dividers. This indicates that increasing the number of ribs from 5 to 11 has only a minor effect on air flow distribution which is already uniform. Therefore, no significant improvement is noticed when the number of ribs is increased to 11 .
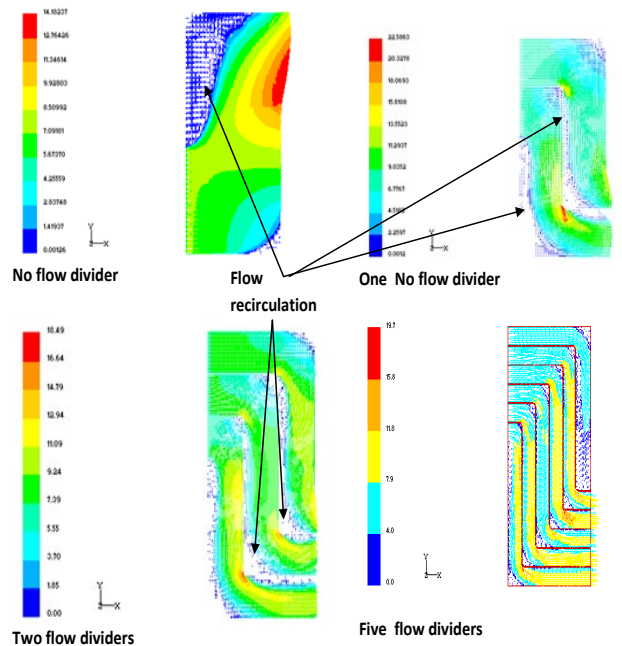

Two flow dividers

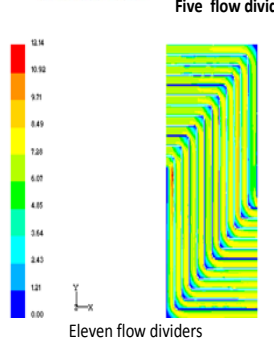

Fig. 8 Air velocity contours in the heat exchanger.

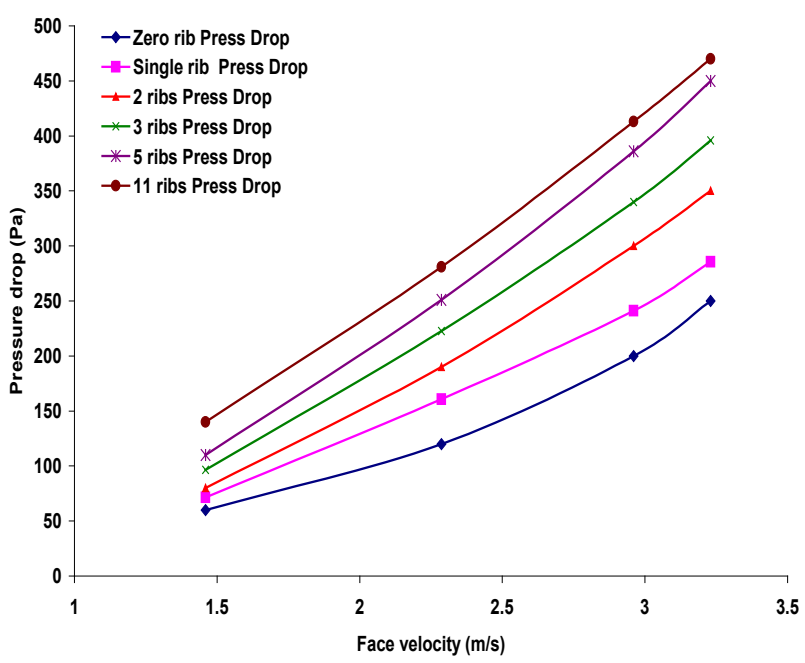

Fig. 9 Heat exchanger modeled pressure drop for different number of flow dividers. 


\section{CONCLUSION}

User Define Function code was developed and incorporated into FLUENT software to enable the software to simulate moisture diffusion through the permeable 45 gsm paper. The models were validated with experimental measurement, before they were used to simulate the effect of changing the heat exchanger flow number of divider ribs to investigate its effect on sensible and latent effectiveness. It was found that although increasing the number of ribs from zero to five ribs increased the heat exchanger effectiveness, it caused the pressure drop to increase across the heat exchanger. However, increasing the number of ribs from 5 to 11 resulted in only minor increase in the effectiveness which is attributed to the flow dividers ribs which makes the flow more uniform and improve the temperature and moisture distribution. When 5 ribs were used, the flow was in uniform state, and hence, increasing the ribs to 11 makes no improvement to the flow profile. Therefore, it is clear that the most optimum number of ribs is 5 as increasing the number of ribs above 5 would not result in further improvement in air flow and distribution of temperature and moisture.

\section{ACKNOWLEDGEMENT}

The authors would like to acknowledge the financial support received from Universiti Teknologi PETRONAS though it's URIF and YUTP grants to publish this research.

\section{REFERENCES}

Al-Waked, R., Nasif, M. S., Morrison, G., and Behnia, M. 2013. CFD simulation of air to air enthalpy heat exchanger, Energy Conversion and Management. 74: $377-385$.

Al-Waked, R., Nasif, M. S., Morrison, G., and Behnia, M. 2015. CFD simulation of air to air enthalpy heat exchanger: Variable membrane moisture resistance, Applied Thermal Engineering. 84: 301-309.
Al-Waked, R., Nasif, M. S. and Mostafa, D. B. 2018. Enhancing the performance of energy recovery ventilators, Energy Conversion and Management. 171: 196-210.

American Society of Heating Refrigerating and Air-Conditioning Engineers (ASHRAE). 2016. ASHRAE handbook-HVAC systems and equipment. Atlanta (GA): ASHRAE Inc.

Cengel, Y. A. 2006. Heat and mass transfer: A practical approach. $3^{\text {rd }}$ edition. Singapore: McGraw-Hill.

Kroger, D. K. 2004. Air-cooled heat exchangers and cooling towers. Tulsa (USA): Penn Well Corp.

Mardiana-Idayu, A. and Riffat, S. B. 2012. Review on heat recovery technologies for building applications, Renewable Sustainable Energy Reviews. 16(2):1241-1255.

Min, J. C., and Duan, J. F. 2016. Comparison of various methods for evaluating the membrane-type total heat exchanger performance, International Journal of Heat and Mass Transfer. 100: 758-766.

Nasif, M. S., Al- Waked, R., Behnia, M., and Morrison, G. 2012. Modeling of air to air enthalpy heat exchanger, Heat Transfer Engineering. 33(12): 1010-1023.

Nasif, M. S., Al-Waked, R., Morrison, G., and Behnia, M. 2013. Air to air fixed plate enthalpy heat exchanger, performance variation and energy analysis. Journal of Mechanical Science and Technology. 27(11): 3541-3551.

Sabekab,S., Tissb,F., Chouikhab,A., and Guizani, R. 2018. Numerical investigation of heat and mass transfer in partially blocked membrane-based heat exchanger: Effects of obstacles forms, Applied Thermal Engineering. 130: 211-220.

Vakiloroaya, V., Samali, B., Fakhar, A. and Pishghadam K. 2014. A review of different strategies for HVAC energy saving, Energy Conversion and Management. 77:738-54.

Yaïci, W., Ghorab, M. and Entchev, E. 2013. Numerical analysis of heat and energy recovery ventilators performance based on CFD for detailed design, Applied Thermal Engineering. 51(1-2): 770-780.

Ye, W., Gao, J., Zhang, X. and Yu, C. W. 2017. Studies of relationship between ventilation, pollution exposure and environmental health of buildings, Indoor Built Environment. 26(2):147-151.

Zhang, L. Z. 2010. Heat and mass transfer in a quasi - counterflow membranebased total heat exchanger, International Journal of Heat and Mass Transfer. 53(23-24): 5478-5486. 